\title{
-TESSITURAS E REINVENÇÕES: (DES)FORMAÇÃO DE PROFESSORES
}

\author{
Viviane Lontra \\ Soymara Vieira Emilião ${ }^{(*)}$ \\ O que é impalpável \\ Mas \\ Pesa \\ o que é sem rosto \\ mas \\ fere \\ o que é invisível \\ mas \\ dói \\ (Orides Fontela, Advinha) $^{1}$
}

A epígrafe nos remete às impressões sobre como as formações continuadas de professores, de alcance nacional, são apresentadas às professoras da escola básica: impalpável e sem rosto. Por isso, pensar a temática da formação nos remete à variedade de sentidos que são expostos aos docentes pelas instâncias do poder público: jogos de poder, correlação de forças, disputas de narrativas. São criações justificadas na "baixa" aprendizagem dos estudantes brasileiros, endossadas nos resultados dos testes de larga escala, que "demoniza os professores" (PINAR, 2008) e coisifica os estudantes. Aqueles que possuem seus saberes, conhecimentos e experiências desqualificados são estigmatizados (ELIAS; SCOTSON, 2000) com a marca do "fracasso" escolar, reforçando a histórica subalternização e culpabilização das vítimas.

Esse artigo pretende trazer a noção de (des)formação a partir da discussão de três ideias latentes nos diferentes espaçostempos ${ }^{2}$ de formação e que estão largamente presentes no imaginário social: a crença em um conhecimento "potente", capaz de "preparar" para todos os desafios da docência; as impossibilidades das políticas serem aplicadas tal como foram pensadas/escritas; e o

\footnotetext{
${ }^{(*)}$ Viviane Lontra. Professora de Educação Básica do Colégio de Aplicação da Universidade Federal do Rio de Janeiro (UFRJ); Graduada em Pedagogia pela UFRJ; mestre em Educação pelo Programa de Pós-graduação em Educação (PPGEdu) da Universidade Federal do Estado do Rio de Janeiro (UNIRIO); Doutoranda em Educação pelo PPGE/UFRJ.
}

Soymara Vieira Emilião. Pedagoga e professora da Rede Municipal de Niterói; Mestre em Educação pelo Programa de Pós-graduação em Educação (PROPed) da Universidade do Estado do Rio de Janeiro (UERJ).

${ }^{1}$ Professora e poetisa. Nasceu em São Paulo (1940) e morreu na miséria em um sanatório em Campos do Jordão (1998). Escolhemos seus poemas como fios líricos na tessitura desse artigo por dialogarem com as reinvenções cotidianas, objeto de nosso estudo.

${ }^{2}$ Aprendemos com os estudiosos do cotidiano a juntas palavras na intenção de inventar novos significados: "princípio da juntabilidade" que concede sentido e significado diferentes dos usuais, quando de sua separação (ALVES, 2001). 
pensamento que abissaliza (SANTOS, 2007) e invisibiliza saberesfazeres tecidos cotidianamente nas escolas.

$\mathrm{O}$ artigo defende a (des)formação como possibilidade que surge nas frestas das formações continuadas quando reúnem professores e seus diversos fios de saberes e experiências, entendendo a impossibilidade de controle do que é criadocompartilhadoexperienciado nos cotidianos das escolas e nos encontros docentes.

O termo (des)formação surgiu em um encontro das autoras na formação do Pacto Nacional pela Alfabetização na Idade Certa (PNAIC). Passamos a usar o termo entre nós como uma rebeldia irônica à medida que se aclarava a percepção de que havia uma sutil imposição de modelos fixos de docência, criança, ensino e aprendizagem indiciados nos materiais "formativos".

Longe da ideia de que há um momento em que a formação se cristaliza, os encontros entre/com professores passaram a ser reconhecidos como espaçostempos onde aprendemos que a docência acontece no ineditismo, nas redes que tecemos nos cotidianos das escolas e salas de aula, em movimentos de não-linearidade, na surpresa, na incerteza, na circulação entre diferentes saberes e nãosaberes. Adaptamos, modificamos, inventamos, combinamos, usamos sentidos, intuições, pistas, indícios (GINZBURG, 1989), táticas gazeteiras e operações astuciosas (CERTEAU, 2013) cotidianamente.

Como usuárias (CERTEAU, 2013) de diversas formações continuadas oferecidas nos últimos anos aos professores da educação básica (PROFA ${ }^{3}$, PROINFANTIL ${ }^{4}$, PROLETRA$\mathrm{MENTO}^{5}, \mathrm{PNAIC}^{6}$ ) percebíamos que os encontros entre/com professores entrelaçavam saberes e provocavam lembranças, narrativas, conversas (MATURANA, 2002), trocas, fofocas (ELIAS E SCOTSON, 2000) empoderando e fortalecendo a autoria pedagógica. Passamos a entender a formação de professores como (des)formação na/da/com a prática, tecendo reflexões que possibilitam pensar a docência para além das lógicas dominantes cientificistas e colonialistas.

As reflexões de Santos (2006) nos ajudam a compreender que todo conhecimento é autoconhecimento, dessa forma entendemos que não existe momento fixo que nos torna

\footnotetext{
${ }^{3}$ Programa Nacional de Formação de Professores Alfabetizadores lançado em dezembro de 2000 pela Secretaria de Educação Fundamental do Ministério da Educação (SEF/MEC).

${ }^{4}$ Programa Nacional de Formação Inicial para Professores em Exercício na Educação Infantil lançado em 2005.

5 Programa Nacional de Formação Continuada de Professores lançado em 2008 para a melhoria da qualidade de aprendizagem da leitura/escrita e matemática nos anos/séries iniciais do ensino fundamental.

${ }^{6}$ Pacto Nacional pela Alfabetização na Idade Certa cujo objetivo é assegurar que todas as crianças estejam alfabetizadas até os oito anos de idade, ao final do $3^{\circ}$ ano do ensino fundamental. Uma de suas ações constitui-se em curso presencial, oferecido aos professores alfabetizadores desde 2013.
} 
"preparados" para a docência, porque ela se tece nas interações, no arquipélago de subjetividades (SANTOS, 1996) que somos e que nos vemos envolvidos desde que nascemos, por isso nos (des)formamos diariamente nas redes que tecemos dentrofora das escolas.

Este texto estrutura-se em três partes: em primeiro lugar, mergulha nos estudos nos/dos/com os cotidianos (ALVES, 2003), base teoricametodológica que fundamenta a pesquisa. Em segundo lugar, dialoga com narrativas de professores que partilharam seus processos de (des)formação. À guisa de conclusão trazemos fios que possibilitam a reinvenção cotidiana de nós mesmos.

\section{FUNDAMENTOS TÉORICOMETODOLÓGICOS:}

Os estudos nos/dos/com os cotidianos (ALVES, 2003) escolares são a base teórica que nos possibilita pensar a formação docente como (des)formação, erguendo o que vivenciamos nas escolas à condição de espaçostempos privilegiados de produção dos conhecimentos, crenças e valores, que dão sentido e direção à relação práticateoriaprática (ALVES, 2008).

Essas pesquisas têm o compromisso políticoepistemológico de buscar um modo de convivência pesquisador-universo pesquisado em que haja respeito mútuo, desenvolvendo relações horizontais com professores das escolas pesquisadas, "institucionalizando, nessa relação, a ideia da validade dos diversos saberes e do necessário diálogo entre eles, para além da hierarquia atuante nos modos dominantes de fazer pesquisa." (OLIVEIRA, 2005, p.100 e 101).

Oliveira (p. 99-100) também destaca que, rompendo com as relações de poder fundamentadas na hierarquia que define quais saberesfazeres são "melhores" ou mais importantes, as pesquisas buscam, no cotidiano das escolas, compreender xs professorxs, seus modos de trabalhar e os valores que deles participam, sem um caráter de julgamento e estabelecimento de "certo" e "errado".

Assumindo o mundo em sua complexidade (MORIN, 2007), buscamos apreender o que nos é dado em sua unidade e multiplicidade, ou ainda, nas palavras de Morin, na sua unitas multiplex; trata-se de, abdicando do entendimento de um tempo linear e de determinações causais, ao modo das concepções tradicionais, pensar as (des)formações como imprevisíveis, circulares, recursivas e transdisciplinares.

Partimos da compreensão que professores são praticantespensantes (OLIVEIRA, 2012) e reafirmamos a necessidade de marcar a opção epistemológica de que "não há prática que não integre uma escolha política e que não há política que não se expresse por meio de práticas e que por elas não seja influenciada", por isso o trabalho foi tecido a partir do conceito de 
políticaspráticas (OLIVEIRA, 2013), partindo do entendimento de que a atuação dxs professores nos/com os currículos praticados está intrinsecamente em diálogo com seus sentiresfazeres. Segundo Oliveira (2012, p. 90):

Os currículos pensadospraticados são criação cotidiana dos praticantespensantes do cotidiano escolar, por meio de processos circulares em que se enredam conhecimentos, valores, crenças e convicções que habitam diferentes instâncias sociais, diferentes sujeitos individuais e sociais em interação.

Nas pesquisas da professora Regina Leite Garcia (2003) nos reconhecemos professoresperquisadorxs. Encontramos e construímos novas explicações para os problemas que enfrentamos nos cotidianos, aprendemos a ver com outros olhos e escutar o que antes não ouvíamos, observando com atenção o que antes não percebíamos, relacionando o que não parecia ter qualquer relação (p.21).

$\mathrm{Na}$ tessitura desse trabalho usamos os cinco movimentos considerados por Alves (2001; 2003; 2008) como fundamentais nas pesquisas nos/dos/com os cotidianos. Em primeiro lugar, mergulhamos com todos os sentidos no que nos propusemos estudar; nos desconstruímos, virando de ponta cabeça o que pensávamos sobre formação, conhecimento e currículo, compreendendo que as teorias limitam o que, de fato, é tecido no "chão da escola"; entendemos a necessidade de "beber em todas as fontes" não negligenciando os estudos da área da educação, mas dando ênfase às vivências, à literatura e às narrativas chegando ao quinto passo, a literaturalização da ciência.

Os estudos de Maturana (2002) também contribuem para o conceito de (des)formação que propomos nesse texto. Com ele aprendemos que o central na convivência humana é o amor, as ações que constituem o outro como legítimo outro na realização do ser social, uma:

harmonia fundamental que não destrói, que não explora, que não abusa, que não pretende dominar o mundo natural, mas que deseja conhece-lo na aceitação e respeito para que o bem estar humano se dê no bem estar da natureza em que se vive. Para isso é preciso aprender a olhar e escutar sem medo de deixar de ser, sem medo de deixar o outro ser em harmonia sem submissão. (p.34)

Para nós, esses aspectos estão presentes na perspectiva da (des)formação tanto no movimento de aceitação e respeito por si mesmo quanto na aceitação e respeito pelo outro, horizontalizando as relações e os saberesfazeres.

Com base no que temos vivenciado nas formações e nas salas de aula é possível inferir que a docência é uma aprendizagem complexa que acontece cotidianamente à medida que nos desvelamos para aprender com. Deslocando a visão de professores "transmissorxs" de 
conhecimentos já elaborados para a de "professores-autorxs" das próprias práticas, abrimo-nos para a possibilidade de criar, de inventar, de construir novas formas de aprenderensinar.

Mais do que absorver uma teoria pronta, os relatos que apresentamos neste texto parecem constatar o quanto aprendemos com as conversas. São provocações que nos trazem a ideia de que precisamos rever paradigmas, precisamos nos (re)inventar a cada dia porque quando passamos a acreditar numa outra episteme abrimos possibilidades de, na relação com nossos pares, produzir sentidos outros.

\section{NARRATIVAS DAS (DES)FORMAÇÕES}

Assumir a autoria pedagógica é dispor-se a desfazer, a trama e a forma que aprisionam o fazer docente. É criar, inventar, descobrir outrasnovas possibilidades.

Reconhecemos que os encontros, as conversas com professores e as narrativas não são dados pré-existentes, mas são produzidos nas redes que se tecem o tempo todo, em todos os lugares. São negociações, traduções impossíveis de serem representadas, que ajudam na desinvisibilização dos processos de (des)formação dos saberespráticas que acontecem cotidianamente dentrofora das escolas.

As marcas dos cotidianos estão presentes nas narrativas dxs professores que apresentamos nesse texto. Dialogamos com os sujeitos que "vivem, convivem, inventam, usam, praticam, habitam, ocupam nesses cotidianos [...]. Trata-se de entender que também aqueles que vivem, de fato, esses cotidianos são os legítimos autores/autoras dos discursos "com" os "cotidianos" (FERRAÇO, 2003, p. 168). Dessa forma, as narrativas além de darem visibilidade aos praticantespensanes das escolas, também os afirmam como protagonistas desse estudo, fazendo "valer as dimensões de autoria, autonomia, legitimidade, beleza e pluralidade de estéticas dos discursos dos sujeitos cotidianos" (grifo do autor). Os afirmam como heróis comuns (CERTEAU, 2013) e anônimos, no anonimato.

A diretora falou que, se eu faço o PNAIC, o resultado da minha turma na Avaliação Nacional de Alfabetização (ANA) tinha que ser o melhor. Disse para ela que prova não prova nada e que não vim aqui para aprender como dar prova. Estou me refazendo, me desconstruindo, ampliando a minha compreensão de ser professora. Não é uma prova de avaliação externa que vai marcar meus conhecimentos nem os da minha turma. (Carla; Professora de uma escola da rede municipal de educação de Niterói; 2014) 
No ano que vem a diretora já disse que eu vou continuar com a minha turma no $3^{\circ}$ ano e vou ter que usar os Cadernos Pedagógicos. Meus alunos vão ter que fazer a prova elaborada pela prefeitura e os cadernos têm toda a matéria que cai nessa prova, mas eu não quero me prender. Ela disse que não preciso fazer além, basta usar o caderno, mas só tem Matemática, Português e Ciências. Como assim?! Eles não precisam da História??? Bem, eu vou usar, mas não vou me prender a isso. Eu conheço os meus alunos e na hora a gente dá uma resposta, a gente ajuda e eu vou ajudar muito mesmo. (Angélica; Professora de uma escola da rede municipal de educação do Rio de Janeiro; 2015).

As formações que vêm sendo propostas subjazem a concepção de conhecimento como um objeto impessoal e descontextualizado - torna-se assim, mercadoria: quanto mais acumulado, maior a chance de proficiência dos educandos. Esse modo de entender o conhecimento abissaliza e invisibiliza saberesfazeres tecidos diariamente nas salas de aula com a "potente" ideia de pensamento único e conhecimento homogêneo, desperdiçando experiências (SANTOS, 2011).

As epistemologias do Sul propostas por Santos (2010, 2011) nos encorajam a pensar outrasnovas formas de conhecer/saber alternativas à dominação que subalterniza, coloniza e invalida formas de conhecimentos que não se enquadram nos padrões estabelecidos/reconhecidos pela Ciência Moderna. Elas procuram não desperdiçar experiências e investem em um diálogo horizontal entre conhecimentos, denominado por ele como justiça cognitiva, que seria alcançada através da ecologia de saberes, que reconhece e valida a diversidade epistemológica procurando combater o desperdício dos saberes silenciados, um ato de relacionar-se não hierárquico e não linear. Com ele entendemos que o conhecimento é interconhecimento, reconhecimento e autoconhecimento (SANTOS, 2010, p. 157).

Partindo da premissa de que a racionalidade moderna subtrai a pluralidade do mundo, entendemos que as propostas de formações tendem a não reconhecer os infinitos conhecimentos tecidos em rede pelos professores nos diversos espaçotempos da docência e propomos a (des)formação como possibilidade de desinvisibilizar experiências vividascompartilhadas pelos praticantespensantes dos currículos nos/dos/com os cotidianos, reconhecendo como potente tudo o que acontece.

Estou aqui em mais um sábado, cansada, sonolenta, mas disposta a estudar, trocar, aprender e ensinar muito. Acho que são visíveis as minhas mudanças. Entrei no grupo muito desacreditada de formações, sempre iguais e também desestimuladas com o meu trabalho. Com o compartilhamento das ideias, as conversas com as colegas, os debates, acho que minhas aulas ficaram mais ricas, os jogos e brincadeiras ocuparam 
mais espaços, meu trabalho está mais em diálogo com a realidade e estou mais atenta aos que meus alunos dizem e pensam. (Viviane; Professora de uma escola da rede municipal de Niterói; 2015).

A gente sempre ajuda nessas provas porque elas não provam nada! Meus alunos são importantes. Para a prefeitura eles são números, mas para nós são pessoas e eu avalio do jeito que eu quero e acredito. (Heitor, Professor de uma escola da rede municipal de educação do Rio de Janeiro; 2015).

As narrativas trazem evidências de que, se de um lado professores são entendidos como meros reprodutores/executores de planejamentos idealizados nos gabinetes por "pensadores", de outro, são criadores que inventam, bricolam, fazem o que acreditam para além da obsessão homogeneizadora: "pensam mais na emancipação do que na avaliação" (SÜSSEKIND; PINAR, 2014, p. 28).

Süssekind (2014) levanta as (im)possibilidades de tais propostas regulatórias (SANTOS, 2004) serem implantadas tal qual foram pensadas, pois, como afirma Certeau (2013, p.38), “o cotidiano se inventa com mil maneiras de caça não autorizada". Diante do imposto, manipulamos o produto, através de nossas redes de saberesfazerespoderes, inserindo criatividade e pluralidade, modificando regras e subvertendo as relações de poder e de pretenso controle. No lugar de uma formação, vivemos a (des)formação. Como praticantes (CERTEAU, 2013), fabricamos, a partir das sucatas, em rede com outras possibilidades.

Inicio mais esse ano de encontro com nosso grupo, animada e feliz. Sei que aprenderemos juntas e misturadas. Sei também que o material didático não vai chegar a tempo e quando isso acontecer olharemos para as páginas finais e suas sugestões para os encontros e confirmaremos que fizemos muito melhor do que seus formuladores podiam supor. (Claudia; Professora de uma escola da rede municipal de educação de Niterói; 2013).

Sabe de uma coisa? Pode aparecer o que quiser, pode ter resolução, pacto, caderno, pode ter cabresto, pode ter regra, prova... na escola a gente faz o que a gente quer, o que a gente sabe! (Eduardo; Professor de uma escola da rede municipal de educação do Rio de Janeiro; 2015).

Eles acham que não somos capazes... sabemos fazer plano de curso e queria fazer o meu, com meus alunos, mas já vem tudo pronto, tudo mastigado... querem que a gente engula, mas isso a gente não aceita. Fazemos o que acreditamos, do nosso jeito. (Fernanda; Professora de uma escola da rede municipal de educação do Rio de Janeiro; 2015). 
Mergulhando com todos os sentidos (ALVES, 2008) nos/dos/com os cotidianos compreendemos que os professores, a partir das sucatas, vivem contínuos processos de (des)formações nos espaçostempos de multiplicidade de saberesfazeres, nas práticas comuns (CERTEAU, 2013), nas táticas cotidianas tidas como insignificantes pela modernidade e entendidas aqui como potentes.

As redes de saberesfazeres, possibilitadas nas (des)formações, contribuem na tessitura de práticas pedagógicas solidárias, coletivas, prazerosas e cidadãs. Fios que se entrelaçam e se entretecem formando outros/novos significados, que possibilitam a produção de diferentes, complexas e múltiplas oportunidades de pensar, viver e sentir a docência, ensejando que os componentes desta rede se arrisquem em práticas autorais.

Eles acham que estamos aqui pela bolsa de R \$200,00, mas estão enganados. Devem pagar, é mais que justo porque estamos fora do nosso horário de trabalho. Mas estou aqui é para me fortalecer, aprender, trocar, me abastecer. Eu faria mesmo que não tivesse essa bolsa, como já fiz outras formações. Mas sempre construímos relações fraternas, e esse afeto vai mexendo com a gente, faz a gente perder o medo, mistura com as novidades, com as experiências dos colegas, aí a gente vai reelaborando nossas práticas, reinventando uma outra professora. (Alessandra; Professora de uma escola da rede municipal de educação do Rio de Janeiro; 2014).

Durante esse tempo aprendi tanto! Foi doído muitas vezes, porque tive que desconstruir muita coisa que foi colocada dentro de mim. Ao mesmo tempo foi muito prazeroso, pois tive a oportunidade de aprender com minhas colegas de rede, tive a chance de fazer diferente. Foi um espaço de construção/desconstrução, prenhe de saberes que circularam entre nós. Me emocionei, pensei, repensei, agi, reagi e fui encorajada pelo grupo a tentar o diferente. (Bianca; Professora de uma escola da rede municipal de educação do Rio de Janeiro; 2015).

Sempre quis ser professora. Cursei o antigo Normal e fiz Pedagogia. Ao entrar numa sala de aula de um CIEP no Morro do Alemão vi que pensava que sabia tudo, mas não sabia absolutamente nada. Foram momentos de muita aprendizagem, descobertas, desesperos. Aprendi a ser professora com aqueles alunos. Não adiantava chegar com planejamento lindo, era preciso "sentir o clima" antes de qualquer proposta, era preciso ouvir os silêncios, os gritos. Era preciso usar muita intuição, todos os sentidos. Era preciso paciência, controle emocional, respeito ao outro. Era preciso me sentir parte daquele grupo e sim, conseguimos ser um grupo! Não dava pra ficar seguindo cartilhas e orientações vindas de outras instâncias, era preciso criar a nossa. (Viviane; Professora da rede federal de educação básica; 2013) 
Práticas emancipatórias nas formações são desinvisibilizadas quando compartilhamos nossas narrativas, úmidas pelas experiências dos compartilhamentos afetivos, do prazer da docência, do encorajamento de novas práticas e do desejo de aprenderensinar. Os cotidianos são compreendidos como espaçostempos de descobertas, de aprendizagens, de (des)formações significativas e provisórias de ser professores. Com Azevedo (2004, p. 13), entendemos que a possibilidade de compreender o compreender do outro reside, ao mesmo tempo, na possibilidade de se compreender como sujeito em formação em redes culturais, abrindo-se, da mesma forma, para a compreensão do outro, se formando em outras redes.

\section{CONSIDERAÇÕES FINAIS:}

O estudo realizado traz a experiência dos encontros com/de professores como espaços potentes na produção de práticaspolíticas (OLIVEIRA, 2013) de (des)formação. Reconhecemos a busca de refletir sobre as (des)formações vividascompartilhadas no e com o cotidiano, no e com o encontro com outro e com nós mesmas.

Com a audácia de desobedecer à colonização da escola, que diz que professores são "transmissores" do saber, buscamos a desobediência, nossa e dos outros, subvertendo a lógica hierárquica e centralizadora que abissaliza conhecimentos, desperdiça experiências e invisibiliza (SANTOS, 2010) as práticasteoriaspráticas (ALVES, 2008) criadas pelos professores nos cotidianos das escolas.

Nesse sentido, podemos dizer que as (des)formações são microvilosidades produzidas nas reflexões e ações dos praticantes (CERTEAU, 2013) que colocam em jogo suas experiências e sentidos, sutis dobras, produzindo outrasnovas compreensões sobre docência, escolas e currículos. Docência, nessa perspectiva, entendida como artesania, produção autônoma, original, criativa, autêntica e autoral, que entrelaça conhecimentos e produz espaçostempos ricos de criações, reinvenções e ações.

Pretendemos que este estudo se transforme em diálogo do qual possam participar aqueles que lutam para romper com a desigualdade social e com a injustiça cognitiva presente não só nas escolas, como na sociedade como um todo. Que possamos caminhar no sentido de valorizar/desinvisibilizar os saberesfazeres daqueles que vêm sendo historicamente negados como produtores de conhecimentos. Que reinventemos nossos caminhos nos encontros, porque, como diz a poetisa: 


\author{
A teia, não \\ mágica \\ mas arma, armadilha \\ a teia, não \\ morta \\ mas sensitiva, vivente \\ a teia, não \\ arte \\ mas trabalho, tensa \\ a teia, não \\ virgem \\ mas intensamente \\ prenhe
}

(Orides Fontela, Teia) 


\section{REFERÊNCIAS}

ALVES, Nilda. Decifrando o pergaminho - o cotidiano na escola nas lógicas das redes cotidiana. In: OLIVEIRA, Inês B.; ALVES, Nilda. Pesquisa no/do cotidiano das escolas, sobre redes de saberes. Rio de Janeiro: DP\&A, 2001.

. Sobre movimentos das pesquisas nos/dos/com os cotidianos. Revista Teias. Rio de Janeiro, ano 4, n. 7-8, Jan./Dez. 2003.

Decifrando o pergaminho - os cotidianos das escolas nas lógicas das redes cotidianas. In: OLIVEIRA, Inês B.; ALVES, Nilda. Pesquisa nos/dos/com os cotidianos das escolas, sobre redes de saberes. Rio de Janeiro: DP\&A, 2008.

AZEVEDO, Joanir G. De "abobrinhas" e "troca de figurinhas". In: professores: possibilidades do imprevisível. Rio de Janeiro: DP\&A, 2004. ; ALVES, Neila G. (Orgs.). Formação de

CERTEAU, Michel de. A invenção do cotidiano 1: As artes de fazer. 20 ed. Rio de Janeiro: Vozes, 2013.

ELIAS, Norbert; SCOTSON, John. L.; Os estabelecidos e os outsiders: sociologia das relações de poder a partir de uma comunidade. Trad. Vera Ribeiro e Pedro Süssekind. Rio de Janeiro: Jorge Zahar Editor, 2000.

FERRAÇO, Carlos E. Eu, caçador de mim. In: GARCIA, Regina L. (Org.). Método: pesquisa com o cotidiano. Rio de Janeiro: DP\&A, 2003.

FONTELA, Orides. Poesia reunida 1969-1996. São Paulo: Cosac Naify; Rio de Janeiro: 7 Letras, 2006.

GINZBURG, Carlo. Mitos, Emblemas e Sinais. São Paulo: Cia das Letras, 1989.

GARCIA, Regina L. (Org.). A formação da professora alfabetizadora: reflexões sobre a prática. 4. ed. São Paulo: Cortez, 2003.

MATURANA, Humberto. Emoções e linguagem na educação e na política. Belo Horizonte: UFMG, 2002.

MORIN, Edgar. Introdução ao pensamento complexo. Porto Alegre: Sulina, 2007.

OLIVEIRA, Inês B. Currículos praticados: entre a regulação e a emancipação. Rio de Janeiro: DP\&A, 2005.

O Currículo como criação cotidiana. Petrópolis: DP et Alii, 2012.

Currículo e processos de aprendizagemensino: Políticaspráticas Educacionais Cotidianas. Currículo sem Fronteiras, [s.1.] v. 13, n. 3, p. 375-391, set./dez. 2013.

PINAR, William. A equivocada educação do publico nos Estados Unidos, In: GARCIA, Regina L.; MOREIRA, Antônio F. Barbosa. (Orgs). Currículo na Contemporaneidade: incertezas e desafios. São Paulo: Cortez, 2008.

SANTOS, Boaventura S. Pela mão de Alice: o social e o político na pós-modernidade. São Paulo: Cortez, 1996.

. (Org.). Conhecimento prudente para uma vida decente: um discurso sobre as ciências revisitado. São Paulo: Cortez, 2004.

Um discurso sobre as ciências. 4. ed. São Paulo: Cortez, 2006.

Para além do pensamento abissal: das linhas globais a uma ecologia de saberes. Novos estud. - CEBRAP [online], n. 79, p. 71-94, 2007. Disponível em: <http://www.scielo.br/scielo.php?script=sci_arttext\&pid=S010133002007000300004\&lng=en\&nrm=iso>. Acesso em> 17 ago. 2014.

. A Gramática do tempo: para um nova cultura política. 3. ed. São Paulo: Cortez, 2010.

- A crítica da razão indolente: contra o desperdício da experiência. Para um novo senso comum: a ciência, o direito e a política na transição paradigmática. v.1., 8 ed., São Paulo: Cortez, 2011.

SÜSSEKIND, Maria L. As (im)possibilidades de uma Base Comum Nacional. In: Revista e-Curriculum. São Paulo, v. 12, n. 03 p. 1512 - 1529 Out./Dez. 2014. Disponível em: <http://revistas.pucsp.br/index.php/curriculum/article/view/ 21667>. Acesso em: 12 fev. 2015.

; PINAR, William. Quem é William F. Pinar? Petrópolis: DP et Alii, 2014. 


\section{RESUMO}

Este artigo discute três ideias presentes nas formações: a crença em um conhecimento "potente", as impossibilidades das políticas serem aplicadas tal como foram pensadas/escritas e o pensamento que abissaliza e invisibiliza saberesfazeres tecidos nas escolas. A abordagem epistemológica teóricometodológica inscreve-se nas pesquisas nos/dos/com os cotidianos à caça do pormenor que provoca entendimentos outros sobre a potência dos encontros de/com professores. O texto traz narrativas e relatos que sugerem que aprendemos a ser professores nas redes que tecemos nos cotidianos das escolas, em movimentos de nãolinearidade. Propõe um entendimento da formação de professores na/da/com a prática que nos possibilitam pensá-la como (des)formação para além das lógicas cientificistas e colonialistas.

Palavras-chave: Currículos pensadospraticados, Estudos do cotidiano; Formação docente.

\section{TESSITURES AND REINVENTIONS: TEACHER (UN)TRAINING}

\section{ABSTRAT}

This article discusses three ideas presents in the formations: the belief in a "potent" knowledge, the impossibilities of the policies to be applied as they were thought/written and the thought that abyss and invisible to know how to make fabrics in schools. The theoretical and methodological epistemological approach fits in with the research in/from/with daily hunting of detail that causes understandings others about the power of dating/with teachers. The text brings narratives and reports that suggest that we have learned to be teachers in the networks we weave in the daily life of schools, in movements of non-linearity. It proposes an understanding of the formation of teachers in the practice with which we can think of it as a deformation beyond the scientific and colonialist logic.

Keywords: Thoughtpracticed curriculum; Daily life studies; Teacher training.

\section{TESITURAS Y REINVENCIONES: (DES)FORMACIÓN DE PROFESORES}

\section{RESUMEN}

Este artículo discute tres ideas presentes en las formaciones: la creencia en un conocimiento "potente", las imposibilidades de las políticas que se aplican tal como fueron pensadas/escritas y el pensamiento que abisice e invisibiliza los conocimientos de los tejidos en las escuelas. El enfoque epistemológico teóricometodológico se inscribe en las encuestas en los/as/con los cotidianos a la caza del detalle que provoca otros entendimientos sobre la potencia de los encuentros de/con profesores. El texto trae narrativas y relatos que sugieren que aprendemos a ser profesores en las redes que tejemos en los cotidianos de las escuelas, en movimientos de no linealidad. Propone un entendimiento de la formación de profesores en la/de la práctica que nos posibilitan pensarla como (des) formación más allá de las lógicas cientificistas y colonialistas.

Palabra clave: Currículos pensadospracticados, Estudios de la vida cotidiana; Formación docente. 